DOI: $10.15593 / 2224-9354 / 2020.4 .11$

УДК 316.37:316.61

\title{
T.A. Tonexa
}

\section{ЭМЕРДЖЕНТНЫЕ ОБРАЗОВАНИЯ СИСТЕМЫ ЛИЧНОСТЬ-ОБЩЕСТВО}

Представлен авторский взгляд на системы социального человека и человеческого сообщества. Выделяются основные направления в научных исследованиях, изучающих индивидуальное и социальное в условиях современного этапа развития общества: цифровизация общества; инновации и инновационные процессы в социальной жизни; общество потребления; социальная атомизация и дезинтеграция современного общества; проблема нормативности в условиях современного технико-технологического общества. Автор предлагает рассматривать социального человека и человеческое сообщество не в их изолированном состоянии, а как сложно образованную систему, требующую отойти от монодисциплинарных и даже междисциплинарных исследовательских позиций, в которых всегда сохраняется иерархия интересов, поддерживающая фрагментарность знаний об изучаемом объекте. Для преодоления разрывов в знаниях о человеке требуется встать на позицию системного подхода, позволяющего приблизиться к пониманию и объяснению эмерджентных образований.

Предложена авторская теоретическая модель-схема формирования эмерджентных образований сложного симбиоза личности и общества. Она позволяет обосновать, что социальный человек, являясь мельчайшей единицей социальной системы, при объединении в физическом плане с себе подобными способен продуцировать эмерджентные образования. В свою очередь общество не является ни простой суммой объединившихся субъектов, ни свойством какой-либо части, но вместе с тем предстает как феномен, возникший, существующий и способный развиваться вследствие постоянного взаимодействия людей не только в пространстве, но и во времени (межпоколенные взаимодействия). Другие эмерджентные образования, локализованные на индивидуальном уровне, создают личность.

Ключевые слова: индивидуальное, социальное, человек, личность, общество.

Современное общество сопряжено с широким кругом преобразований в социокультурной, духовной, экономической и других сферах. В поле зрения исследователей попадают вопросы, связанные с различными сторонами жизнедеятельности общества.

1. Цифровизаџия общества поднимает ряд вопросов, связанных с изменениями, в социальной реальности детерминированными встраиванием цифровых технологий в традиционную систему общественной жизни.

Исследователи педагогической сферы бьют набат, отмечая, «что избыточное использование гаджетов в раннем возрасте способно затруднить дальнейшую социализацию человека, отрицательно сказаться на формировании у него коммуникативных навыков» $[1$, с. 72$]$. Социологи полагают, что можно

(C) Топеха Т.А., 2020

Топеха Татьяна Анатольевна - канд. социол. наук, доцент кафедры социальной работы и конфликтологии ФГБОУ ВО «Пермский государственный национальный исследовательский университет», e-mail: topeha@rambler.ru. 
и нужно управлять происходящими в социуме социальными процессами, понимая и «учитывая природу качественно новых реалий» [2, с. 49] социума, приобретающего фрагментарные и дисперсные черты.

Исследователи в области психологии отмечают дискуссионность вопроса «о степени корреляции цифровой социализации с традиционными видами социализационных траекторий» [3, с. 6]. Ведя разговор о социализации в условиях виртуальной среды, они дифференцируют его по трем направлениям «виртуальной социализации, киберсоциализации, медиасоциализации» [4, с. 6] и выделяют три этапа в процессе «интернет-социализации» [4, с. 9-10]. Обращают внимание на становление интернета как нового мощного агента социализации, значимого как для вторичной, так и первичной социализации [5]. Задаваются вопросом, на кого ориентируются в условиях виртуального пространства современные люди и кто является «хозяином контента». Ведь именно в условиях взаимодействия цифровых технологий и психики пользователя, с одной стороны, «формируются новые механизмы взаимодействия человека с реальностью, новые психические феномены», а с другой, проявляется возможность получения глубокой и качественной оценки изменений, рисков и угроз [6, с. 134].

2. Инновации, ставшие неотъемлемой частью социальной жизни, заставляют исследователей пересмотреть понятие «капитал». Все чаще звучат категории «социальный капитал», «человеческий капитал», отмечается существенная роль в экономическом потенциале региона человеческого капитала [7], внутриорганизационного доверия для инновационной деятельности предприятий [8], ставится вопрос о зависимости между инновациями и социокультурными приобретениями личности (ценностными ориентациями в сфере идеологии и нравственности) [9].

3. Общество потребления - аспект, акцентирующий внимание на вопросах смысловых ориентиров. Он давно занимает умы ученых, но в современных условиях предлагается рассматривать его не как феномен, а как идеологию: «речь идет о стремлении навязать мировоззрение, в котором обмен и потребление товаров служат основным механизмом социального прогресса» [10, c. 44]. Это позволяет увидеть причины смещения ценностных ориентиров от созидательной деятельности к жизни, смысловые ориентиры которой направлены на первоочередное удовлетворение социально-символических потребностей. Ставится вопрос: «Глобализация - это социальная эволюция или, наоборот, разрыв материального и духовного фактора, грозящий деградацией и потерей духовности» [11]. Он рождается на основе преобразования коммуникации из социально-психологического процесса, богатого иррациональными компонентами (эмоции, культура, нравственность), в процесс сугубо рациональный, становящийся товаром. 
Можно видеть и определенное столкновение взглядов, одни полагают, что сама логика развития рыночной экономики подталкивает человечество к индивидуальной свободе и автономии, продуцирующей инфантилизацию большей части взрослого населения, которое, отгородившись, не желает брать на себя ответственность, проявляет неуважение к созидательной деятельности. Потребность саморазвития уходит в небытие, поскольку современный человек полагает, что важнее получить максимум для себя, жить в собственное удовольствие, нежели думать и обременять себя заботами тех, кто находится рядом и нарушает ауру счастья [12]. Другие же, соглашаясь с растущей рационализацией социальной системы, видят в информационно-коммуникативных технологиях не только возможности для удовлетворения потребностей, но и базу для формирования социальных общностей, становления новой социальной площадки, к которой будут применимы все традиционные механизмы социального регулирования [13].

4. Социальная атомизация связана с проблемой не просто развития общества, а сохранения человеческих сообществ, сохранения социокультурных достижений человечества, которые могут быть безвозвратно утрачены.

Некоторые авторы обращают внимание на деполитизированность общества. Одной из главных причин маргинализации гражданской позиции (в условиях РФ) является именно потребительская культура, стремительно ворвавшаяся в 90-е гг. XX в. Социальная практика меняет не только модели удовлетворения индивидуальных потребностей, но и общественно-политическую ситуацию [14].

Другие, делая акцент на поколенном расслоении и усилении именно межпоколенных конфликтов, негативно влияющих на сохранение базовых ценностей общества, задаются вопросом поиска точки опоры, которая могла бы консолидировать общество и тем самым обеспечить ему духовную безопасность [15]. Делают вывод, что не только сами люди вносят вклад в собственное разобщение, но и власть, стремящаяся деятельность по решению проблем заменить иллюзией общности и совместных действий [16].

5. Проблема социальной нормативности на современном этапе связана с формированием новых границ социально приемлемого и неприемлемого.

Люди озабочены проблемой одиночества, выходящей за пределы социальной атомизации. Проявление одиночества, как правило, носит ярко выраженный социально-психологический характер и выступает одной из основных причин суицидального поведения. Современный человек оказывается заложником постоянных стрессов, вызванных как нарастающим информационным потоком, так и высоким уровнем динамичности социальной ситуации, требующей «быть готовым к резкому изменению обстановки, места жительства, профессиональной деятельности, характера личностных отношений с окружающими» [17, с. 127]. Он не может рассчитывать на поддержку социального 
окружения и по причине нарастающего социального безразличия и пониманием, что в решении проблем он может положиться только на себя самого.

Ведутся исследования девиаций, вызываемых проникновением техникотехнологических новаций в повседневную жизнь человека. В пространстве интернета люди разных возрастов проводят все больше времени, и встает вопрос о разграничении социальных норм, регулирующих поведение в реальной жизни и цифровом мире [18]. Психологические исследования направлены на поиск сходных признаков между лицами, подверженными различным формам аддиктивного поведения [19]; изучение деструктивного и аутодеструктивного поведения [20] в условиях новой социальной реальности.

Все эти обособленные исследовательские темы сливаются в одной точке, на стыке социального-индивидуального и во взаимосвязи личности и общества. Возникает не только требование уточнения используемых понятий, но и поднимается вопрос взаимодействия представителей различных социальных и гуманитарных наук при изучении системы личность-общество.

Если в период становления социологии Дюркгейм поднимал вопрос о разграничении предметного поля, то в настоящее время, когда институционализация наук, занимающихся изучением сложного симбиоза личности и общества, завершена и каждый осознает научные пределы, возникает новая проблема. Необходимо постичь эмерджентные свойства, возникающие у каждой стороны этого симбиоза и образуемые их слиянием, поскольку часто именно они оказываются вынесены за скобки в монодисциплинарных исследованиях.

Чтобы выработать целостный взгляд, необходимо встать на системную позицию и теоретически определить на основе богатого эмпирического материала, накопленного науками порознь, точки пересечения и разрыва между социальным и индивидуальным.

Человека как социального субъекта можно взять в качестве точки отсчета, для определения особенностей перехода простого к сложному. Для этого необходимо рассмотреть дифференцирующую линию понятий человек - личность - индивидуальность.

В социально-гуманитарных науках трудно обнаружить единство и в определениях этих категорий, и в методологических подходах к их изучению. Каждая наука выделяет в связке этих понятий собственные акценты, вынося за скобки то, что не входит в сферу ее интересов, тем самым упрощая и обедняя феномен человека как самостоятельной социальной единицы. Философия делает акцент на общечеловеческой перспективе и, несмотря на использование понятия личность, ей ближе категория «человек», обозначающая собирательный образ социального субъекта в пространстве и времени. Психология чаще использует категорию «личность», акцентируя внимание на уникальности, что позволяет утверждать, ей намного ближе категория «индивидуальность». Социология использует разные конструкты, однако для сферы ее исследований 
ближе категория «личность», которая акцентирует внимание на социальной сути человека. Поскольку человек как мельчайшая система, входящая в общество, по своей природе включает в себя разные аспекты, которые в связанности и взаимодействии позволяют возникнуть многим эмерджентным образованиям, то говорить о человеке, вынося за скобки его биологическое, социальное или психологическое начало, не корректно.

Личность есть эмерджентное образование, которое возникает не только как продукт процесса социализации, но и как продукт процесса индивидуализации, под влиянием сложных и слаженных процессов интериоризации и экстериоризации. Поэтому ни одна из наук, не может претендовать на главенство своих позиций, для целостного понимания человека как мельчайшего социального образования, являющегося механизмом образования сложной социальной системы «общество».

Социальные субъекты ${ }^{1}$ немыслимы вне трех позиций проявления социальной активности:

1) внешне фиксируемая данность, представленная конкретной ситуацией, событиями и расположенная вне субъекта;

2) позиция субъекта - наблюдатель; она характеризуется пониманием и объяснением той внешней данности, которая окружает субъект;

3) позиция субъекта - непосредственный участник; субъект не только понимает, но объясняет и обосновывает собственную свободно выбранную стратегию поведения.

Условие внешней ситуации - это социальные факты. Однако являются ли социальные факты единственной причиной детерминации социальной жизни? Если да, то тогда все в действиях социальных субъектов, равно как в функционировании и развитии социума, однозначно предрешено. Вместе с тем действительность, которую мы наблюдаем, позволяет нам усомниться в столь упрощенной детерминации социальной жизни. Поэтому мы должны допустить, что социальные субъекты не только оказываются под влиянием социальных фактов, но и влияют на них, изменяя силу и направленность детерминирующего воздействия социальных фактов.

Остановимся подробнее на субъекте, выступающем движущей силой, меняющей социальную ситуацию и социальную реальность. Личность как эмерджентное свойство социального человека является сложным феноменом, возникающим на пересечении целого ряда дихотомических осей ${ }^{2}$ :

1) ось материальности, располагается в диапазоне «грубая материя» (анатомо-физиологические характеристики человека и окружающая его естественная и искусственная природа) - «тонкая материя» (представлена челове-

1 Рассмотрим только людей и их взаимоотношения, хотя рассматриваемая схема может быть экстраполирована и на другие сложные элементы социальной системы.

${ }^{2}$ Возможно, что образующих личность осей больше. 
ческой психикой, а также широким информационным полем вокруг него имеющим как естественную, так и искусственную природу);

2) ось мерности, располагается в диапазоне «единичное» (состоящее из одной системы) - «многомерное» (несколько связанных и взаимодействующих систем);

3) ось познания располагается в диапазоне «объективный, внешний способ познания» (сходный, единый способ фиксации фактов, событий большинством субъектов, а также единая линия понимания, переживания, объяснения фиксируемых данных) - «субъективный, внутренний способ познания» (уникальный способ фиксации фактов, событий, а также уникальный образ понимания, переживания, объяснения зафиксированных данных).

Эти оси могут визуализировать для нас проявление личности в двух аспектах: статичном и динамичном.

Статичный аспект проявляет «ядро личности», которое представлено устойчивым сложным феноменом, включающим все элементы, образующие целостную систему социального субъекта (ценности, нормы, статусы, роли и другие, в том числе их понимание и стратегия реализации). При этом ядро личности отвечает как за уникальность, так и за общность переживаний, оценок, описания, объяснения происходящих внешних и внутренних событий, ситуаций, фактов. Именно в нем происходит преломление, выделяющее чтолибо, особенно с одновременным нивелированием других аспектов внешнего и внутреннего мира.

Динамичный аспект личности связан с выбором и обоснованием стратегии поведения в результате осмысления и переживания конкретных социальных условий. Посредством установления конкретных взаимодействий с окружающими людьми и миром в целом личность сливается с внешней ситуацией.

При моделировании процесса формирования эмерджентных образований системы личность-общество (рисунок) мы будем выделять:

1) ядро личности (ценности, нормы, статусы, роли и т.д.);

2) динамические свойства личности (переживания, осмысление социальной ситуации и себя в ней, с последующим выбором конкретной стратегии поведения и обоснования своих действий и выборов);

3) взаимодействие с окружающими людьми и миром;

4) внешняя ситуация (факты, события).

Описывая данную схему, мы можем заметить, что некая внешняя ситуация (4) может своим существованием ни на что не оказывать влияния, пока не встретится система, которая, пропуская ее через свое ядро, в его актуальном состоянии не запускает механизм интериоризации (2) и дальнейшей экстериоризации (3). В ходе интериоризации социальный субъект начинает переживать и осмысливать встретившуюся на его пути ситуацию, соотнося ее со своими ценностями, нормами, статусами, ролями и т.п., в результате чего формирует- 
ся некая стратегия поведения, которая проявляется в ходе экстериоризации (взаимодействия с окружающими людьми и миром). Интеракция вносит изменения, отражающиеся во внешней ситуации (4), она становится уже несколько иной, с другим набором данных. Однако в ходе интеракции происходит изменение и в системе социального субъекта, через получение новой информации и запуск процесса рефлексии, влияющего вновь на динамические свойства субъекта, которые могут привести к изменениям в ядре личности, хотя при определенных обстоятельствах ядро может остаться и без изменений. В некоторых случаях можно заметить не просто сохранение, но и укрепление содержательных аспектов ядра личности.

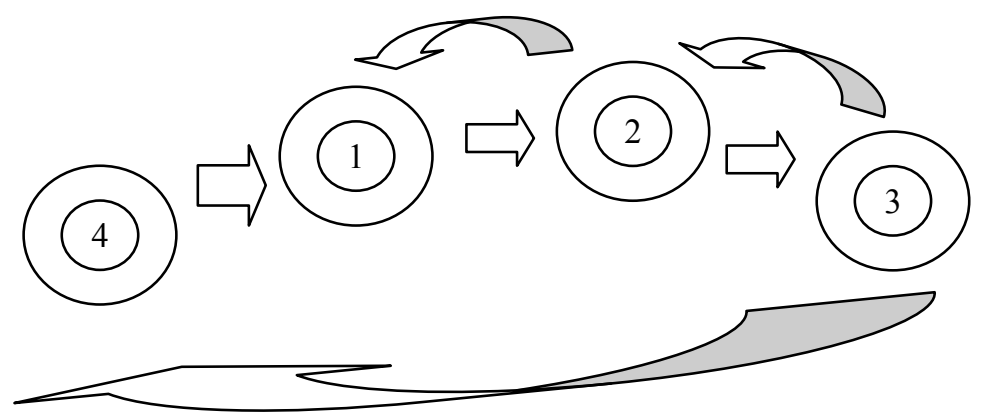

Рис. Модель-схема одного витка формирования эмерджентного образования системы личность-общество

В подтверждение правильности наших построений вспомним основные взгляды на культуру в философии Хайдеггера и Кассирера. Хайдеггер, видя в человеке существо конечное, отмечал, что осознание своей конечности подталкивает к сотворению культуры как собственного мира, мира его «присутствия», в котором все служит средством пользования и самореализации. В этом случае культуру можно в общем виде идентифицировать с обществом как эмерджентным образованием. Другой методологической позиции придерживается Кассирер: человек - существо бесконечное, поскольку культура выступает свободным движением, при исчезновении этой свободы культура застывает и ей приходит конец. В данных двух позициях мы можем видеть не противоположность взглядов на культуру и человека, а диаметрально расположенные методологические позиции, образующие единый континуум, позволяющий увидеть переход единичного к общему и обратно. Хайдеггер позволяет нам понять смысловые позиции зарождения общества, которое не является простой суммой индивидов, но формируется как эмерджентное образование, возникающее в ходе взаимодействия индивидов. Позиция Кассирера позволяет увидеть функционирование социальной системы и привлекает внимание к возможной кульминационной точке, когда общество может распасться на части. Общество может атомизироваться вследствие прекращения свободного 
движения человека не как биологического существа, а существа, наделенного эмерджентными свойствами, позволяющими ему продлить свое существование за пределами физической мерности, т.е. осуществляя свободное психологическое, социально-психологическое, социальное и социокультурное движение, через сотворение своей бесконечности, воплощения частицы себя в окружающих людях и последующих поколениях.

Именно культура как человеческий продукт, способный обретать самостоятельную жизнь в качестве эмерджентного образования, является средой развития личности каждого социального субъекта. По отношению к этому внешнему социальному факту он выступает не только учеником, но и творцом, поскольку происходит не только проникновение в каждого нового человека этой физически не осязаемой материи, но и активное, свободное отношение каждого человека к ней. Это отношение проявляется не только в принятии, но и отвержении всей или части материи под названием социокультурное, социальное начало, являющееся основой общества. Здесь можно видеть свободу человека в его творческом воздействии - дополнение (через искусство, науку и обычную социальную практику) этой материи новыми свойствами, оказывающими влияние на других индивидов, находящихся рядом ${ }^{3}$

\section{Список литературы}

1. Смирнов В.В. Феномен цифровой зависимости в условиях информационного общества (социально-психологический аспект) // Высшее образование сегодня. - 2019. - № 4. - С. 72-76.

2. Кравченко С.А. Цифровые риски, метаморфозы и центробежные тенденции в молодежной среде // Социологические исследования. - 2019. - № 8. C. $48-57$.

3. Морозова Е.В., Плотичкина Н.В., Попова К.И. Государство как агент цифровой социализации // Вестник Пермского университета. Политология. 2019. - Т. 13, № 2. - С. 5-16.

4. Лучинкина А.И. Модель интернет-социализации личности // Информационно-психологическая безопасность личности в интернет-пространстве. Симферополь, 2015. - С. 6-13.

5. Ершова Р.В. Цифровая социализация личности в эпоху глобальных перемен // Прикладная психология на службе развивающейся личности: сб. науч. ст. и материалов XVI науч.-практ. конф. с междунар. участием. - Коломна, 2019. - С. 49-54.

${ }^{3}$ В условиях информационного общества слово «рядом» теряет свое пространственное значение, поскольку «рядом» с продуктом творчества могут оказаться люди, пространственно сильно удаленные, и в прежние времена они, вероятно, не могли бы соприкоснуться ни с творцом, ни с его творением. 
6. Ершова Р.В. Пойманные одной сетью // Цифровое общество как культурно-исторический контекст развития человека: сб. науч. ст. и материалов III междунар. конф. - Коломна, 2020. - С. 132-137.

7. Зыбина Ю.П. Компоненты человеческого потенциала в социальном измерении (на примере Курской области) // Актуальные проблемы развития человеческого потенциала в современном обществе: материалы V междунар. науч.-практ. конф. - Пермь, 2018. - С. 121-127.

8. Балезина Е.А., Форостян В.В. Уровень доверия как один из элементов социального капитала организации // Актуальные проблемы развития человеческого в современном обществе: материалы IV междунар. науч.-практ. конф. - Пермь, 2017. - С. 4-7.

9. Бурко В.А. Взаимосвязь социального капитала и модернизационных ценностей в студенческом коллективе // Logos et Praxis. - 2019. - T. 18, № 3. C. $131-139$.

10. Орлов М.О. Общество потребления как источник социальных и духовных рисков // Известия Саратовского университета. Новая серия. Философия. Психология. Педагогика. - 2020. - Т. 20, № 1. - С. 43-46.

11. Короп М.М. Коммодификация коммуникации: цена и ценность [Электронный ресурс] // Мир науки. Социология, филология, культурология. 2020. - № 1. - URL: https://sfk-mn.ru/PDF/38SCSK120.pdf.

12. Армен А.С. Духовно-нравственный кризис общества потребления // Духовное производство в эпоху позднего капитализма: материалы междунар. науч. конф. - Донецк, 2020. - С. 230-236.

13. Щекотуров А.В. Социальные медиа: становление нового макдональдизированного института // Вестник РУДН. Социология. - 2020. - Т. 20, № 1. C. $18-29$.

14. Ильин А.Н. Социальная атомизация и политический эскапизм в условиях общества потребления // Философия и гуманитарные науки в информационном обществе. - 2018. - № 2 (20). - С. 47-66.

15. Шнуренко Т.И. Интеграция ценностного поля поколенных групп в контексте духовной безопасности // Научное мнение. - 2019. - № 12. С. $125-129$.

16. Антипьев К.А. Пути и средства повышения социальной активности групп местного сообщества // Современное общество: вопросы теории, методологии, методы социальных исследований. - Пермь, 2018. - Т. 1. - С. 9-14.

17. Демидова Е.Н., Демидов В.П. Одиночество современного человека как социальный фактор рекламы // Научно-технические ведомости СПбГПУ. Гуманитарные и общественные науки. - 2015. - № 2 (220). - С. 126-132.

18. Солдатова Г.У., Рассказова Е.И. Соблюдение правил общения онлайн и офлайн: межпоколенческий анализ // Психологический журнал. - 2019. Т. 40, № 4. - С. 73-84. 
19. Семеняк И.В., Ершова Р.В. Психофизические особенности интернетзависимых лиц и лиц, зависимых от употребления наркотиков // International Journal of Medicine and Psychology. - 2020. - T. 3, № 2. - С. 84-91.

20. Солдатова Г.У., Илюхина С.Н. Аутодеструктивное поведение подростков и молодежи в Интернете: анализ кейсов // Цифровое общество как культурно-исторический контекст развития человека: сб. науч. ст. и материалов III междунар. конф. - Коломна, 2020. - С. 371-376.

\section{References}

1. Smirnov V.V. Fenomen tsifrovoi zavisimosti v usloviiakh informatsionnogo obshchestva (sotsial'no-psikhologicheskii aspekt) [The phenomenon of digital dependence in the information society (social and psychological aspect)]. Vysshee obrazovanie segodnia, 2019, no. 4, pp. 72-76.

2. Kravchenko S.A. Tsifrovye riski, metamorfozy i tsentrobezhnye tendentsii $\mathrm{v}$ molodezhnoi srede [Digital risks, metamorphoses and centrifugal trends among the young people]. Sotsiologicheskie issledovaniia, 2019, no. 8, pp. 48-57.

3. Morozova E.V., Plotichkina N.V., Popova K.I. Gosudarstvo kak agent tsifrovoi sotsializatsii [The state as an agent of digital socialization]. Vestnik Permskogo universiteta. Politologiia, 2019, vol. 13, no. 2, pp. 5-16.

4. Luchinkina A.I. Model' internet-sotsializatsii lichnosti [Model of Internet socialization of personality]. Informatsionno-psikhologicheskaia bezopasnost' lichnosti v internet-prostranstve. Simferopol, 2015, pp. 6-13.

5. Ershova R.V. Tsifrovaia sotsializatsiia lichnosti $v$ epokhu global'nykh peremen [Digital socialization of personality in the era of global changes]. Prikladnaia psikhologiia na sluzhbe razvivaiushcheisia lichnosti. Proceedings of XVI Sci.-Pract. Conf. with Int. participation, Kolomna, 2019, pp. 49-54.

6. Ershova R.V. Poimannye odnoi set'iu [Caught by one network]. Tsifrovoe obshchestvo kak kul'turno-istoricheskii kontekst razvitiia cheloveka. Proceedings of III Int. Conf. Kolomna, 2020, pp. 132-137.

7. Zybina Iu.P. Komponenty chelovecheskogo potentsiala v sotsial'nom izmerenii (na primere Kurskoi oblasti) [Components of human potential in the social dimension (on the example of Kursk region)]. Aktual'nye problemy razvitiia chelovecheskogo potentsiala v sovremennom obshchestve. Proceedings of V Int. Sci.Pract. Conf. Perm, 2018, pp. 121-127.

8. Balezina E.A., Forostian V.V. Uroven' doveriia kak odin iz elementov sotsial'nogo kapitala organizatsii [Trust level in information sources as one of the organization's social capital elements]. Aktual'nye problemy razvitiia chelovecheskogo v sovremennom obshchestve. Proceedings of IV Int. Sci.-Pract. Conf. Perm, 2017, pp. 4-7. 
9. Burko V.A. Vzaimosviaz' sotsial'nogo kapitala i modernizatsionnykh tsennostei $\mathrm{v}$ studencheskom kollektive [Interrelation of social capital and modernization of values in fellow student collective]. Logos et Praxis, 2019, vol. 18, no. 3, pp. 131-139.

10. Orlov M.O. Obshchestvo potrebleniia kak istochnik sotsial'nykh i dukhovnykh riskov [The society of consumption as a source of social and spiritual risks]. Izvestiia Saratovskogo universiteta. Novaia seriia. Filosofiia. Psikhologiia. Pedagogika, 2020, vol. 20, no. 1, pp. 43-46.

11. Korop M.M. Kommodifikatsiia kommunikatsii: tsena i tsennost' [Commodification of communication: Price and value]. Mir nauki. Sotsiologiia, filologiia, kul'turologiia, 2020, no. 1, available at: https://sfk-mn.ru/PDF/38SCSK120.pdf.

12. Armen A.S. Dukhovno-nravstvennyi krizis obshchestva potrebleniia [Moral crisis of the consumer society]. Dukhovnoe proizvodstvo v epokhu pozdnego kapitalizma. Proceedings of Int. Sci. Conf. Donetsk, 2020, pp. 230-236.

13. Shchekoturov A.V. Sotsial'nye media: stanovlenie novogo makdonal'dizirovannogo instituta [Social media: The development of a new mcdonaldized institution]. Vestnik RUDN. Sotsiologiia, 2020, vol. 20, no. 1, pp. 18-29.

14. Il'in A.N. Sotsial'naia atomizatsiia i politicheskii eskapizm v usloviiakh obshchestva potrebleniia [Social atomization and political escapism in a consumer society]. Filosofiia $i$ gumanitarnye nauki $v$ informatsionnom obshchestve, 2018, no. 2 (20), pp. 47-66.

15. Shnurenko T.I. Integratsiia tsennostnogo polia pokolennykh grupp $\mathrm{v}$ kontekste dukhovnoi bezopasnosti [The integration of the axiological field of generational groups in the context of spiritual safety]. Nauchnoe mnenie, 2019, no. 12, pp. $125-129$.

16. Antip'ev K.A. Puti i sredstva povysheniia sotsial'noi aktivnosti grupp mestnogo soobshchestva [Ways and means of increasing the social activity of groups of local community]. Sovremennoe obshchestvo: voprosy teorii, metodologii, metody sotsial'nykh issledovanii, Perm, 2018, vol. 1, pp. 9-14.

17. Demidova E.N., Demidov V.P. Odinochestvo sovremennogo cheloveka kak sotsial'nyi faktor reklamy [Loneliness of modern man as a social factor of advertising]. Nauchno-tekhnicheskie vedomosti SPbGPU. Gumanitarnye $i$ obshchestvennye nauki, 2015, no. 2(220), pp. 126-132.

18. Soldatova G.U., Rasskazova E.I. Sobliudenie pravil obshcheniia onlain i oflain: mezhpokolencheskii analiz [Following communication rules online and offline: Intergenerational analysis]. Psikhologicheskii zhurnal, 2019, vol. 40, no. 4, pp. 73-84.

19. Semeniak I.V., Ershova R.V. Psikhofizicheskie osobennosti internetzavisimykh lits i lits, zavisimykh ot upotrebleniia narkotikov [Psychophysical features of Internet-addicted persons and drug addicted people]. International Journal of Medicine and Psychology, 2020, vol. 3, no. 2, pp. 84-91. 
20. Soldatova G.U., Iliukhina S.N. Autodestruktivnoe povedenie podrostkov i molodezhi v Internete: analiz keisov [Self-destructive behavior of teenagers and young people on the Internet: Cases analysis]. Tsifrovoe obshchestvo kak kul'turnoistoricheskii kontekst razvitiia cheloveka. Proceedings of III Int. Conf. Kolomna, 2020, pp. 371-376.

Оригинальность $89 \%$

Получено 31.07.2020 Принято 28.08.2020 Опубликовано 28.12.2020

\title{
T.A. Topekha
}

\section{EMERGENT FORMATIONS OF THE PERSONALITY-SOCIETY SYSTEM}

\begin{abstract}
The article gives an author's view of the systems of social human and human community. The main avenues in scientific research of individual and social phenomena at the current stage of social development are distinguished: digitalization of society, innovation and innovative processes in social life, consumer society, social atomization and disintegration of modern society, the problem of social norms in modern technical and technological conditions. The author proposes to consider social individuals and human community not in their isolated state but rather as a complex system that requires moving away from monodisciplinary and even interdisciplinary approaches that feature a hierarchy of interests, supporting the fragmentation of knowledge about the object concerned. To overcome the gaps in our knowledge about humans, it is necessary to take a systemic approach that would grant us a better understanding of emergent formations.

The author advances a theoretical model-scheme of emergent formations of complex symbiosis of personality and society. It allows us to justify that an individual as the smallest unit of the social system is able to produce emergent formations, when physically consolidated with other people. In turn, a society is neither a simple sum of individuals taken together nor a property of any part. However, it may also be treated as a phenomenon that has emerged, exists and is able to develop due to the constant interactions of people both in space and in time (intergenerational interactions). Other emergent formations localized at the individual level produce personality.

Keywords: individual phenomenon, social phenomenon, human, personality, society.
\end{abstract}

Tatyana A. Topekha - Candidate of Sociological Sciences, Department of Social Work and Conflictology, Perm State National Research University, e-mail: topeha@rambler.ru.

Received 31.07.2020 Accepted 28.08.2020 Published 28.12.2020 